\title{
Cost Savings for Manufacturing Lithium Batteries in a Flexible Plant
}

Paul A. Nelson

Argonne National Laboratory, 9700 S. Cass Avenue, Argonne IL 60439 USA

nelsonp@anl.gov

Shabbir Ahmed (Corresponding author)

Argonne National Laboratory, Bldg. 200, 9700 S. Cass Avenue, Argonne IL 60439

USA

ahmeds@anl.gov, Tel: (630) 252-4553, Fax: (630) 972-4553

Kevin G. Gallagher

Argonne National Laboratory, 9700 S. Cass Avenue, Argonne IL 60439 USA

kevin.gallagher@anl.gov

Dennis W. Dees,

Argonne National Laboratory, 9700 S. Cass Avenue, Argonne IL 60439 USA

dees@anl.gov

Page 1 of $\mathbf{5 0}$ 


\begin{abstract}
The flexible plant postulated in this study would produce four types of batteries for electric-drive vehicles - a hybrid (HEV), 10-mile range and 40-mile range plug-in hybrids (PHEV), and a 150-mile range battery-electric (EV). The annual production rate of the plant is 235,000 battery packs (HEV: 100,000; PHEV10: 60,000; PHEV40: 45,000; EV: 30,000). The cost savings per battery pack calculated with the Argonne BatPaC model for this flex plant $v s$. dedicated plants range from $9 \%$ for the EV battery packs to $21 \%$ for the HEV packs including the battery management systems (BMS). The investment cost savings are even larger, ranging from $21 \%$ for EVs to $43 \%$ for HEVs. The costs of the 1.0-kWh HEV batteries are projected to approach $\$ 714$ per unit and that of the EV batteries to approach $\$ 188$ per kWh with the most favorable cell chemistries. The best single indicator of the cost of producing lithiummanganate spinel/graphite batteries in a flex plant is the total cell area of the battery. For the four batteries studied, the price range is $\$ 20-24$ per $\mathrm{m}^{2}$ of cell area, averaging $\$ 21$ per $\mathrm{m}^{2}$ for the entire flex plant.
\end{abstract}

\title{
Keywords
}

Lithium ion, automotive batteries, flexible plant, manufacturing cost 


\section{Introduction}

The demand for batteries for electric-drive vehicles may be too low for some years to come to economically produce them in plants dedicated to one type of vehicle battery. Also, upgrades to the products and orders from new customers must be easily undertaken with existing processing equipment. In this report, we term the type of plant that can produce batteries for different types of vehicles a flexible plant and abbreviated it as flex plant. Manufacturers of automobile batteries are already taking this approach. Batteries for vehicles can be produced at moderate cost if the batteries for several types of vehicles are produced in a single plant with only moderate changes to the production lines to accommodate the various products. With the emergence of grid electrical energy storage, lithium-ion batteries for grid storage can be co-produced in a flex plant with transportation batteries, which may serve to bring down the unit cost of the batteries. For over a decade Argonne has designed batteries for electric vehicles based on modeling with Microsoft Office Excel spreadsheets [1-4]. This effort was extended to calculating the cost of manufacturing lithium ion batteries [5-12]. The modeling program, $\mathrm{BatPaC}$ [5-7], which resulted from these previous studies, was used in this study to evaluate the feasibility of manufacturing several different types of batteries on the same manufacturing line to achieve economies of scale. Cost projections for Li-ion battery manufacturing have also been reported by others. Patry et al. [8] reported that thicker electrodes are attractive for reducing cost and mass, but detrimental for power and aging characteristics. Sakti et al. [9] concluded from their analysis that 
economies of scale are reached at 300 MWh of battery capacity in a plant. Cost modeling and projections have also been reported by TIAX [10] and Mock [11]; battery manufacturing has been addressed by Shawn et al. [12], and Mareike et al. [13] asserts the importance of the manufacturing process optimization on battery performance and production costs; Benjaafar et al. [14] and Balakrishnan et al. [15] discuss flexible manufacturing processes.

Studies with BatPaC have shown that the major costs for manufacturing lithiumion vehicle batteries are 1) materials, 2) plant facilities, and 3) labor and energy. The materials costs per unit of production are not greatly affected by the production rate of a single battery manufacturing plant because the materials are similar for batteries for all applications. The electrode materials are made by chemical manufacturers, the current collector foils by metal suppliers and the separators by specialty manufactures of battery supplies. These materials are thus priced like commodities and BatPaC treats their prices as inelastic on the scale of a single plant producing 100,000 battery packs per year or less. On the other hand, the capital cost of the plant and the cost of labor are greatly affected by the scale of operations at every stage of the processing. Only very large plants with the highest speed electrode coating equipment and the most automated cell and module handling and testing equipment can approach minimum costs. This would require production of 200,000 to 500,000 large all-electric vehicle (EV) batteries per year, greater than at any lithium-ion factory now in production. The smaller hybrid-electric (HEV) and 
plug-in hybrid vehicle (PHEV) batteries would require even higher production levels measured in units per year in dedicated plants to approach minimum costs.

The overall thesis of this study is that the scale of production can be increased and, thus unit cost decreased, by producing several types of batteries in the same plant. As stated above, this requires that the batteries can be produced on the same plant production lines with easily made adjustments to accommodate the different battery designs. That the unit cost will decrease with increasing throughputs at each processing step is not at issue here because it is a well-established industrial fact [21] and is built into the BatPaC model [6,7]. What is at issue is if batteries of very different capacities and power-to-energy ratios can be designed to be produced on the same line of plant equipment with only slight, rapid adjustments to the equipment settings.

The most common lithium-ion cell designs are cylindrical wound cells, flat wound cells, and prismatic cells with flat plates. We believe that the flex plant approach would be applicable for each of these types of cells. Cylindrical cells have been employed in Tesla batteries with the selection of the standard dimensions of 18650 cells (18-mm diameter x 65-mm length). The electrode strips to be wound would have the same widths for all applications and would vary only in the thickness of the coatings, the composition of the electrode materials, and the lengths of the strips. These differences could be easily accommodated by the coating and 
electrode slitting equipment. After winding and testing the cells, the assembly of the modules and battery packs would be similar for all battery applications.

Flat wound cells could be handled in a flex plant in a similar way to that for the cylindrical cells. It would require that the length of the cell, which determines the width of the electrode strips, be the same for all of the battery applications. Also, if the width and thickness of the cells are to be the same for all applications, the application that requires the smallest cell to meet the voltage requirement with a single string of cells would determine the size of the cell for all applications. That size, however, would have a larger capacity than for the cylindrical design because of the superior heat dissipation characteristic for thin flat cells.

The cell design chosen for the $\mathrm{BatPaC}$ model is the prismatic design with flat plates because that design easily accommodates a wide range of capacities and power-to-energy ratios. And, therefore we have selected that design to facilitate the study.

A major processing step in battery manufacturing today is the coating of the electrode materials onto both sides of current collector foils, which are of aluminum for the positive electrode and usually of copper for the negative electrode. The coating process handles wide sheets of foil materials that are coated with electrodematerial layers that are typically 25 to 100 -microns thick when finished. For a prismatic multi-plate cell, these coated sheets are calendered and slit into individual 
plates. These plates are dried under vacuum, stacked into multi-plate cells with separator sheets between the positive and negative electrodes and then the electrodes are ultrasonically welded to the feedthroughs. To accommodate several types of vehicle batteries in a single plant, the width and length of the plates should be standardized for that plant because changes in the lengths or widths of the electrodes require complex adjustments in some of the steps making automation more difficult and expensive. However, the thickness of the coating can be allowed to vary because the coating process and the steps that follow can easily accommodate changes in the electrode thicknesses. That allowance and variation in the electrode compositions permits the wide range in the power-to-energy (P/E) ratio needed for the various types of vehicle batteries.

Standardizing the electrode widths and lengths will also result in approximately standard cell widths and lengths. The cell thickness, which determines the number of electrodes per cell, has default values in the BatPaC model $[6 \mathrm{~mm}$ for hybrid electric vehicles (HEV), $8 \mathrm{~mm}$ for plug-in hybrid electric vehicles (PHEV) and $12 \mathrm{~mm}$ for electric vehicles (EV)]. For the flex plant, the cell thickness can be varied to adjust the cell capacity and battery voltage.

In the BatPaC design, the above standards would result in the modules for all vehicle types having approximately the same length and height and varying only moderately in width (the dimension determined by the thickness of the cells and their number per module). The similarities in the cells and modules favor increased 
use of automation in the handling of the great numbers of these parts in a flex plant and, thus lead to economies of scale. Because of the standard electrode sizes, the height of all battery packs produced in a flex plant would vary by only a few millimeters and could be set to allow fitting the packs under the back seat of sedans.

To demonstrate the efficacy of the proposed flex plant, it is necessary to show that batteries of a wide range of capabilities from a HEV battery with a high powerto-energy ratio $(\mathrm{P} / \mathrm{E})$ to an $\mathrm{EV}$ battery with a low $\mathrm{P} / \mathrm{E}$ can be designed with electrodes of the same width and length. It is also necessary to demonstrate that the flex plant can produce the batteries at substantially less cost than dedicated plants for each battery type producing at the levels needed for each battery type. To illustrate the feasibility of accomplishing these goals, this study designed batteries that meet a set of representative performance goals, shown in Table 1, and calculated their prices when produced both in a flex plant and in dedicated plants at the production rates shown.

Table 1 Example of battery pack parameters and production volumes for manufacturing in a flexible plant

\section{Battery Designs for Flexible Plants}

\subsection{Design Format}

Page 8 of $\mathbf{5 0}$ 
For this study, the basic battery design was that used in the BatPaC model [5-7]. The cell has a prismatic design with a stiff-pouch container as shown in Figure 1. The terminals are almost as wide as the full width of the cell with the positive terminal at one end of the cell and the negative terminal at the opposite end. This construction results in very low resistance in the current collection structure. For this study, the batteries are all liquid cooled with the cells enclosed in hermetically sealed modules (Fig. 2), which are cooled on their exterior surfaces by ethylene glycol-water solution. The module enclosure protects the cell terminals from the coolant, which is an electrolyte, but the module terminals must also be protected with an impenetrable coating.

The modules are enclosed in a battery jacket, which is constructed with a sheet of aluminum on each side of a 10-mm thick layer of ridged, light-weight, highefficiency insulation. The insulation slows the interaction of the battery with the external environment that cools the battery in the winter and heats it in the hot summer weather.

The selected design makes possible detailed calculations of the battery performance and the geometry, weight and materials needed to manufacture the battery. However, we concluded that the cost calculations for this design would be relevant for batteries differing considerably from the selected design approach, because the amounts of the key materials and the processing of these materials are not dependent on the battery design. 
Figure 1. Prismatic cell in stiff pouch container with aluminum conduction channel added for heat rejection from a liquid-cooled module

Figure 2. Module with hermetically sealed aluminum container for liquid cooled batteries

\subsection{Constraints for Ease of Manufacture and Vehicle Packaging}

The following discussion is not directly related to battery manufacture in a flexible plant, but concerns restrictions on the battery design for manufacture in any plant and which are superimposed on constraints related to the flexible plant.

For ease of battery construction, it is most practical to design the battery modules with an even number of cells. This results in both terminals being on the same face of the module without requiring a conductor to shuttle current from the opposite side of the module as would be required for a module with an odd number of cells. Designing for the terminals on the same side of the module simplifies connections and a return conductor within the module would add cost and weight. For the same reasons, if there are groups of cells in parallel within a module there should be an even number of groups of cells. The exception to the rule of an even number of cells in a module is for a HEV battery with a single module. 
The BatPaC model calls for one, two, or four rows of modules in the battery pack. Only EV batteries and some PHEV40 batteries would require more than one row of modules. For such batteries, it is necessary to have an even number of modules.

An additional restriction for the larger batteries is that they must fit the space available in the vehicle. For this study, we assumed that the battery would be placed under the back seat. To meet this restriction, the height of the battery must be no more than about $150 \mathrm{~mm}$ ( 6 inches) and the width less than about $1225 \mathrm{~mm}$. For the PHEV40 batteries in this study, the length of the battery was less than $1225 \mathrm{~mm}$ and only a moderate fraction of the battery would protrude behind the back seat into the trunk. A very large EV battery would protrude further into the trunk, perhaps prompting redesign of the battery and vehicle, which were not undertaken here.

\subsection{Battery Design Constraints Imposed by the Flexible Plant}

In addition to the above constraints on battery design imposed by the need for simplicity of design and the needs of the vehicle, an effort to take full advantage of the economies of scale by manufacturing in a flexible plant imposes additional design restrictions. These restrictions result mainly by selecting the same electrode size for all batteries produced in the plant, as discussed in Section 1. In the standard $\mathrm{BatPaC}$ model, the length-to-width ratio of the positive electrode may be set by the designer and 3.0 is the default ratio, which was also used in this study. However, the 
cell area is allowed to vary to meet the power requirement. Because the number of cells in the pack is set and the number of plates in the cell is restricted by the preset thickness of the cell, varying the cell area to meet the power requirement, as is done in the standard BatPaC model, results in varying the size of the electrodes. In the flex plant, however, the size of the electrode plate is not a variable so the battery power must be changed by varying the number of cells or the number of electrodes within a cell (varying cell thickness), which are both discrete numbers so that the target power for the battery can only be approximated.

Providing the target power is further complicated for batteries of low $\mathrm{P} / \mathrm{E}$ ratio for which the $\mathrm{P} / \mathrm{E}$ ratio is set by the limiting electrode thickness $(100-\mu \mathrm{m}$ is the default limit in $\mathrm{BatPaC})$. The effect of this additional restriction is that the full pack energy is achieved with a thinner electrode providing more area and higher power than called for by the target power.

For lowest cost, the batteries should be designed with a single string of seriesconnected cells and minimum cell count to meet voltage requirements of the power electronics system. This minimizes the number of cells to be manufactured and the complexity of their interconnection. The thicknesses of the electrodes are determined by the P/E ratio and the number of electrodes in a cell by the thickness of the cell. Thus, the size of the electrode ( $\mathrm{x} \mathrm{W}$ ) determines the capacity of the cell in each type of battery. For electrodes of a small size, this will result in a large number of cells for high-energy EV batteries, which would require parallel 
connections to avoid excessive battery voltage. On the other hand, for HEV batteries with large electrodes the pack voltage may be lower than desired. Thus, the challenge for the battery designer and flex plant manager is to select a single electrode size that makes possible the achievement of appropriate voltages for all of the types of batteries being manufactured. The only other variables that they can adjust to achieve this goal are the thickness of the cell and the number of cells in parallel.

\section{Spreadsheet Development}

For this study, we altered the basic BatPaC program $[5,6]$ to meet all of the special restrictions discussed above for manufacturing in a flex plant. The basic change was to set values for the length and width of the electrodes that apply to all types of batteries produced in the flex plant. Other parameters are then iterated by the battery designer to achieve the desired battery power, energy storage, nominal voltage and overall battery dimensions. The parameters that can be varied to achieve these goals are (1) number of cells in each module, (2) number of rows of modules, (3) number of cells in parallel and (4) the thickness of the cells (number of electrodes per cell). The program was designed to make slight adjustments to the target cell thickness to achieve a whole number of electrodes per cell.

\subsection{Spreadsheet Elements for Battery Design}


To facilitate calculations for a single flexible plant, four BatPaC model spreadsheets, one for each battery type were brought together into a single spreadsheet. Each of the worksheets on which calculations are carried out has a section that is dedicated to each of the four types of batteries. These include the worksheets: Chem, Battery Design, Summary of Results, Thermal, Manufacturing Calculations, Price of Modules, Cost Breakdown, and Error Bars. There is only one section in the Cost Input worksheet because the cost input for manufacturing is the same for all of the batteries. The costs of materials are contained in the Chem worksheet, which has separate sections for each battery type to allow different cell chemistries for each battery type.

The BatPaC model, without any adjustments, is capable of calculating the cost for seven batteries in a single spreadsheet. It was decided to retain this capability for each of the batteries to be manufactured in the flex plant and to assign seven levels of manufacturing to each so that the cost of manufacturing in the flex plant can be compared with the costs for dedicated plants of various levels of manufacturing. In addition to the above worksheets, an over-riding data entry worksheet (designated as "Flex") was added in which key design parameters for each battery can be entered in one section, and production levels for the cost calculations can be entered in a second section.

During the calculation, values are automatically taken from the Flex worksheet and entered where the input values normally go in the Battery Design worksheet of 
the BatPaC model for battery power, cell capacity, and cell thickness. Thus, there is no interference with the normal BatPaC method of calculation, but rather a selection of special input values that provide results for the exact desired electrode dimensions and the approximate power and capacity (energy) to meet the needs of the application.

\subsection{Spreadsheet Elements for Battery Cost Estimation}

\subsubsection{Method of Cost Estimation}

The BatPaC cost calculations are based upon the estimated cost of manufacturing in a Baseline Plant and adjusting that cost to account for the ratio of the processing rates for the plant being designed and those in the baseline plant $[5,6]$. The baseline plant produces 100,000 packs per year of PHEV batteries with the following characteristics: cell chemistry $\mathrm{LiN}_{0.8} \mathrm{Co}_{0.15} \mathrm{Al}_{0.05}$-graphite (NCA), $50-\mathrm{kW}$ power, 40-Ah capacity, and 60 cells per pack. In adjusting the cost, each step in the process is considered separately and a characteristic processing rate parameter is assigned (e.g., for electrode coating, area coated per year; for formation cycling, number of cells per year). For each step the cost factors $(C F)$ of $(1)$ annual direct labor hours, (2) capital equipment investment, and (3) plant floor area are calculated from the equation,

$$
C F=\frac{C}{C_{o}}=\left(\frac{R}{R_{o}}\right)^{p}
$$


where $\left(C, C_{o}\right)$ are the costs for the processing rate $\left(R, R_{o}\right)$, respectively, and $p$ is the economy of scale power factor. This general method of estimating costs is well established in industry [22-23] and is particularly useful in calculating costs of closely related products for purposes of comparison.

\subsubsection{Production in Dedicated Plants}

In converting BatPaC for this study, the worksheets were expanded to provide for all four battery types on a single worksheet and to calculate the cost of manufacturing at seven production levels ranging from 10,000 to 100,000 batteries per year for each battery type. Thus, the cost for manufacturing in a total of 28 plants was estimated. This was done to provide costs for production in dedicated plants of various production rates for comparison with costs for production in the large flex plant. The calculations for manufacturing in a flex plant were added to each of the worksheets as described below.

\subsubsection{Production in the Flexible Pant}

The cost of combining the production for the four types of batteries in a single flex plant is distributed among all batteries. This is done by calculating the cost of direct labor, capital equipment and plant space for each operation in the plant for the total production volume for that operation for all four batteries. The economy of scale is taken into account as shown in Equation (1). The rate by which the production is measured depends on the process step; for example it is the number 
of cells produced per year for the welding of the current collector foils to the cell terminal. For that process step, the production rate in the flex plant $(13,120,000$ cells per year) is 2.19 times as much as for the Baseline Plant $(6,000,000$ cells per year) (1) and the power factor for scaling direct labor cost for this operation is 0.7 resulting in a labor cost of 1.73 times that for the Baseline Plant for this operation. This cost was distributed among the battery types in proportion to their share of the production volume for that processing step. The distribution for the main measures of the processing rate in the flex plant is shown in Table 2 .

The EV batteries have the lowest production rate at 30,000 per year, only $13 \%$ of the number of batteries produced per year in the flex plant, but they dominate the need for plant resources-i.e. electrode materials (58\%), electrode coating (46\%), and dry room area (38\%).

Table 2 Distribution of processing rates and dry room area among battery types; 100-mm x 300-mm electrodes.

Most of the operations of the plant require many parallel lines of equipment, which easily accommodate the simultaneous production of four different types of electric-drive vehicle batteries. However the entire electrode coating capacity for the plant could be achieved by two coaters for the positive electrodes and two for the negative electrodes. These coaters would coat both sides of metal foil sheets 
(aluminum for the positive and copper for the negative) of approximately two meters in width of the configuration layout shown in Fig. 3.

Figure 3. Sample layout of electrode coating on current collector foil

It is unlikely that the initial flex plants would be designed with only two coaters for each type of electrode. Four different types of batteries with different electrode coating thicknesses must be produced. There should be at least three coaters available for the positive electrodes and three for the negative electrodes to avoid frequent conversions from one type of electrode to another and to avoid excessive inventories of work in progress. Also, the first flex plants are unlikely to be designed originally as complete plants, but are expected to evolve from smaller plants limited to one or two types of batteries, as discussed below in section 6. These smaller plants would have coating equipment of moderate width, which would be refurbished for use in the full-sized flex plant. Thus, it is expected that the flex plant will have at least three coaters for each type of electrode, with only one as wide as two meters and the other two coaters with 1-to 1.5-meter widths. Some of these coaters may be partially depreciated because of previous use, but no credit is taken for this or for any excess capacity because refurbishing is assumed to bring both the cost (total of new and undepreciated cost) and the value up to that of new equipment for a plant of the same total capacity. 
However, the smaller batteries (especially the HEV and PHEV10 batteries) would be manufactured in short runs during the year lasting only one to several weeks. The electrode coating equipment, for which the throughput is determined by the annual electrode area, would be occupied only $11 \%$ of the total time in coating electrodes for the HEV batteries (Table 2). In a plant dedicated to producing 100,000 HEV batteries (presently, a larger production rate than for any single HEV), the coating equipment would be smaller and slower than in the flexible plant and would cost more per battery pack for equipment and for the operating labor. For the EV battery, however, one or more of the high-speed coating lines would be in continuous use in the flex plant. There would be only moderate economies of scale for the EV battery in the flex plant because the coating equipment for a dedicated plant for 30,000 battery packs per year would already be fast and economical. 3.3 Plant Capacity

Because of the complexity of manufacturing in the proposed flex plant, the plant may frequently operate at partial capacity, especially during the initial years of operation. The provision for operating the plant at a fraction of full capacity is a departure from the regular BatPaC model calculations [5-6], where the model assumes that the plant is operated at $100 \%$ of the design capacity, so an explanation of how the costs were calculated for operating the plant at partial capacity is given here. The cost of materials and labor are calculated for the actual production level. The total capital equipment cost and the plant area are calculated for the full plant capacity (235,000 packs per year). These costs (of capital and plant area) are then attributed to each battery type based on its production rate as a percentage of the total production rate. 
The design production rate for the Baseline Plant and for all plants designed by $\mathrm{BatPaC}$ is based on producing the equivalent of 300 days of full production per year with three 8-hour shifts per day, except two shifts for shipping and receiving. Besides the provision for days off line or at less than full productivity, provision is made for each process step to fall behind schedule and then catchup later. For instance, if fully available, the equipment for coating, calendering, and electrode slitting can exceed the $100 \%$ capacity rate by $29 \%$. Similarly, the excess capacity for final electrode drying is $47 \%$; formation cycling, $29 \%$; cell assembly in the dry room, $37 \%$. Provision is also made for storing work in process at every stage of operation so that work can continue in other parts of the plant by taking work from inventory from a process step that is partially shut down.

Because of these excess capacities and the scheduling of only 300 equivalent full work days in a year, the plant could exceed the rated production capacity by $50 \%$ for a short period (several weeks). On the other hand, there are several reasons why the flex plant might operate at rates far short of its design capacity, especially during its early stages of operation. Initially, the plant area will certainly be larger than necessary to permit future growth. The excess space in each manufacturing department will be sufficient to add equipment as needed. There will be times when the equipment is down for revisions as the plant becomes more extensively automated and personnel are retrained. As the battery mix changes, it will not be possible to have the exact set of equipment that is needed for operation at $100 \%$ of 
the plants capability for every processing operation. Some operations may limit the production rate while others have excessive capacity in anticipation of a near-future change in production goals or product mix.

As the plant matures, it is expected that the capacity factor (production rate/design rate) will approach $100 \%$ because the product mix will become more stable and the strategies to deal with changes in the mix will be developed.

\section{Results of Battery Design Study}

As discussed in section 2.3 , the targets of the battery designer for the battery power and the energy cannot be met exactly with the battery design restrictions imposed by the flex plant. Thus, it was necessary to demonstrate that the deviation from the targeted design value are acceptably small over a wide range of electrode sizes. To study this problem, preliminary calculations were made for five electrode widths from 70 to $110 \mathrm{~mm}$, all with the same length-to-width ratio of 3.0 and for cells of the default thicknesses of BatPaC, which vary with the type of battery. The deviation from the targeted power and energy are illustrated in Figure 4.

Figure 4. Deviations from the targeted power and energy for four types of batteries (see Table 1) for five levels of positive electrode widths and a length-towidth ratio of 3.0. 
For the HEV, and PHEV batteries, the power was within about 5.5\% of the target for all five of the electrode widths (top graph, Fig. 4). The power data for the EV battery is not shown on this graph, because the EV battery had more power than necessary by more than two fold for all five electrode widths because the limiting electrode coating thickness of 100 microns resulted in much higher power-toenergy than required by the application. This result is not due to restrictions imposed by the flex plant, but to properties of the cell chemistry. The energy provided by the four types of batteries as designed for the flex plant with the five different electrode widths were within $6 \%$ of the target energy in all cases as illustrated in the lower graph in Figure 4.

Thus, both power and energy goals can be adequately met for all four battery types when they are designed with electrodes of the same size over a wide range of electrode sizes. As is discussed below, the goals for power and energy can be matched even more closely (within 1 to $3 \%$ ) when the thickness of the cell (number of electrodes per cell) is allowed to vary, rather than being held constant as was done for Figure 4.

The battery designer must also consider the voltage of the batteries in selecting the most advantageous electrode size to be used for all cells produced in the plant. If the cells are made with small electrodes, a large number of cells are needed to meet the power and energy requirement for the entire battery resulting in high voltage and high cost. For the same set of batteries as in Figure 4, the nominal voltages for 
the EV and PHEV40 batteries with a single string of cells were too high for all electrode sizes. On the other hand, the voltage was too low for the PHEV10 and HEV batteries, especially for the larger electrode sizes. To adjust the battery voltage, it was decided that more flexibility was needed in the battery design by considering multiple cells in parallel and deviations from the default cell thicknesses set in the standard BatPaC model. The allowance of varying the cell thickness (number of electrode layers per cell), also results in finer adjustments to the power and energy of the battery, as noted above. With these adjustments, the electrode size of $100-\mathrm{mm}$ width $\times 300$-mm length was selected for this study as it provides acceptable voltage, power and energy for all of the battery types (Table 3). However, any of the electrode sizes shown in Figure 4 would have served well, illustrating the feasibility of designing all of the electric-drive batteries to have the same length and width electrode size.

Table 3 Selected parameters for batteries to meet goals of Table 1 with lithium manganite spinel/graphite (LMO) cell chemistry and 100-mm x 300-mm positive electrodes

The cell capacity and the battery voltage were adjusted by selecting cell thicknesses that differ from the standard BatPaC default values. These adjustments raised the voltages for HEV and PHEV10 batteries and lowered those for the PHEV40 and EV batteries. In addition, the EV battery was designed with two cells in parallel to further reduce the module and battery voltages by $50 \%$. As a result of 
these adjustments, the voltages for all of the batteries are within a reasonable range. Also, the energy storage and vehicle driving ranges are all within 1 to $3 \%$ of the target values.

These calculations demonstrate that it is practical to design batteries for a wide range of $\mathrm{P} / \mathrm{E}$ and total energy, all with the same electrode size varying only the thickness of the electrode coatings. Thus the advantage of achieving economies of scale by producing the main components of the battery cells with a single size is feasible.

\section{Results of Manufacturing Cost Study}

\subsection{Effects on Cost of Over-Sizing and Under-Sizing Battery Energy}

As discussed above, it is not possible to exactly choose the battery power and energy while presetting the electrode dimensions in the flex plant; the battery must be either slightly over sized or under sized because of the need to select a discrete number of cells and electrodes per cell in fitting the battery-design constraints. The effects of battery sizing are illustrated in Table 4 for the EV battery that is intended to meet the targets set in Table 1. The over-sized EV battery is that defined in Table 3 and the undersized battery is similar except it has cells with 42 two-sided positive electrodes instead of 43 such electrodes. 
Table 4 Effects of over sizing and under sizing battery; EV battery with LMO cell chemistry and100-mm x 300-mm electrodes

While the larger battery would cost more, it would also be more valuable because it would provide a longer vehicle range. The cost of energy stored is nearly the same for both cases. The result obtained in sizing this EV battery is representative of the results for all of the batteries in the study and indicates that the cost of energy stored is a meaningful measure in comparing costs calculated for the flex plant.

\subsection{Savings for Manufacturing in a Flexible Plant and Cost Distribution among Battery Types}

The high production rates for each step in the process for manufacturing in a flex plant result in significant economies of scale (Fig. 5) compared to manufacturing in four small plants dedicated to each battery type. In this comparison, both the flex plant and the dedicated plants are producing at full capacity.

Figure 5. Unit cost per battery pack and cost of energy storage (including the BMS) for LMO batteries manufactured at the indicated rates in plants dedicated to a single battery type producing at $100 \%$ capacity (lines) and in a flex plant producing all of the batteries at $100 \%$ of the 235,000 packs per year capacity (markers); all positive electrodes measure $100-\mathrm{mm}$ by $300-\mathrm{mm}$. 
The savings are best shown in the lower graph of Fig 5.1, for which the cost of energy storage is plotted against the production rate for each type of battery, and in Table 5. The smaller HEV and PHEV10 batteries have the most to gain from manufacturing in the flex plant because so much of the cost is due to processing at the low rates of production in the dedicated plants and, therefore, benefit from the large economies of scale in the flex plant. On the other hand, the large numbers of cells and electrodes produced in the dedicated plants for the PHEV40 and EV batteries would result in large economies of scale even though these plants produce only 45,000 and 30,000 batteries per year, respectively. The unit cost savings for the flex plant range from $9 \%$ for the EV battery packs to $21 \%$ for the HEV packs (Table 5). The investment cost savings are even larger, ranging from $21 \%$ to $43 \%$. Another illustration of the economy of scale is observed by noting that the EV battery pack in the flex plant $(30,000$ packs per year in Table 5$)$ costs $\sim \$ 8000$; whereas, a dedicated plant producing the same pack would approach that cost at production levels exceeding 60,000 packs per year, as shown in Figure 5.

Table 5 Distribution of product cost for flexible plant producing LMO batteries with $100-\mathrm{mm} \times 300-\mathrm{mm}$ electrodes including the BMS units

The prices for the batteries as calculated by BatPaC and in this study are the prices the manufacturer would need to charge to receive the average profit for a 
manufactured product. This profit is estimated in BatPaC to be $5 \%$ of total investment after taxes. In actually selling the batteries, the price would be that which the market would bear, which might be higher or lower than the price estimated before production begins. Based on the product cost, which is the price calculated by BatPaC and includes return on investment, the 100,000 HEV batteries produced each year represent $13 \%$ of the flex plant annual cost, whereas the 30,000 EV batteries represent $44 \%$ of that annual cost.

It is of interest to note that the fraction of the product cost for each type of battery (Table 5) is very nearly the same as the fraction of the electrode area (Table 3.2). Thus, the product cost for the batteries manufactured in the Flex Plant is about $\$ 20-\$ 24 \mathrm{~m}^{-2}$ of electrode area for all four battery types and $\$ 21 \mathrm{~m}^{-2}$ for the total production of the Flex Plant.

The relationship between the cost per unit of cell area in the pack and the production volume was further explored and is illustrated in Fig. 6. The cost of the batteries in terms of $\$ /$ total cell area are plotted versus the annual cell area produced resulting in curves for the four battery types which are closely grouped and parallel (no cross-overs). These curves approach very low slopes at production rates of 80 million $\mathrm{m}^{2}$ per year equivalent to $202,000 \mathrm{EV}$ batteries per year or 2.7 million HEV batteries per year. This level of production would be extremely high for 
a plant dedicated to HEV batteries, but it is smaller than the production plant planned by Tesla for large EV batteries ${ }^{1}$ [23]. It is concluded that HEV batteries can approach their minimum cost in the near future only if produced in flexible plants with other types of batteries. To a lesser extent this is also true for PHEV batteries. At a set level of production, the cost of the EV batteries is determined by the total cell area and the maximum thickness limit of the electrode coating, which is 100 microns in BatPaC (Table 3). The HEV and PHEV10 batteries have nearly the same cost per square meter as EV batteries at the same annual rate of area production because the electrode coatings are thinner (saving cost) but this is offset by higher hardware costs for the larger number of cells, modules and battery enclosures associated with that annual production level.

The similarity in the cost per unit area of the batteries in this study results partly from the attempt to select realistic battery-vehicle options. If the PHEV40 battery is converted to a PHEV20 while retaining the same high power, the cost for production in the flex plant will drop to about $\$ 17 \mathrm{~m}^{-2}$, much lower than that for the other batteries. However, the cost savings would be only about $\$ 800$ per battery, a small savings for giving up half the electric range.

${ }^{1}$ (Tesla's Elon) “Musk has said that the plant will cost around $\$ 5$ billion once it's completely operational and that it will comprise about 10 million square feet. Running at full capacity, the factory will produce 500,000 battery packs a year, enough to match what the entire world produces today. Musk needs the factory's titanic economies of scale to reduce by 30 percent the cost of the lithium ion batteries its cars use." 
Figure 6. Cost of battery packs as a function of cell area and production rate for production in plants dedicated to a single type of battery

\subsection{Evaluation of Flex-Plant Costs for Batteries with Differing Cell Chemistries}

The flex plant can easily accommodate electrode materials that differ with the type of battery without sacrificing the gains in economies of scale that accrue to the flex plant. The most significant effect of the choice of cell chemistry is on the cost of the materials. The cost of processing is also slightly affected by changing the cell chemistry because of its effect on the processing rates for some of the steps in the process. The flex plant can accommodate variations in the electrolyte composition.

For ease of evaluation, all of the calculations in the studies discussed above were for LMO cell chemistry, which has good properties for batteries with high power-toenergy requirements (the HEV, PHEV10 and PHEV40 battery targets for P/E are 35, 22.8 and 11.4, respectively). The EV battery in this study, however, has a P/E ratio of only 4.25 , which places more value on the specific capacity of the positive active material and less on achieving low ASI. Thus, NMC-441 $\left[\mathrm{Li}_{1.05}\left(\mathrm{Ni}_{4 / 9} \mathrm{Mn}_{4 / 9} \mathrm{Co}_{1 / 9}\right)_{0.95} \mathrm{O}_{2}\right]$ with a specific capacity of 175 mAh-g-1 $^{-1}$ is better suited to the EV battery than LMO, which has a specific capacity of $100 \mathrm{mAh}^{-1} \mathrm{~g}^{-1}$ even though the use of NMC441 results in higher impedance than LMO. 
We compared the performance and cost for manufacture in flex plants for EV batteries with NMC-441 electrodes with those of the LMO EV batteries of Table 3, We designed the EV batteries with the NMC-441 electrodes to have the same number of cells (160) and the same configuration as for the LMO battery (Table 6).

Table 6 Comparison of EV battery designs with LMO or NMC positive electrodes (100 mm W x $300 \mathrm{~mm} \mathrm{~L})$ manufactured in flex plants

The high specific capacity of the NMC-441 electrode results in the need for fewer electrodes per cell for the NMC batteries than for the LMO batteries. Since the electrode coating thicknesses are the same for both types of EV batteries (the limiting thickness of 100 microns), fewer electrodes results in thinner cells for the NMC-441 battery. The overall result is high specific energy and low cost for energy stored for the NMC EV battery. This result is in spite of the higher cost of the 
positive active material and higher cost per cell area for the NMC battery packs. Substituting NMC chemistry for LMO for the EV batteries produced in the flex plant reduces the cost for the EV battery from 226 to $188 \$-\mathrm{kWh}^{-1}$.

There is a considerable decrease in processing rate for some of the processing steps for the flex plant producing EV batteries with NMC positive electrodes in contrast to the plant producing all of the batteries with LMO electrodes. This has the interesting effect of actually increasing the cost of the smaller batteries produced in the flex plant when NMC batteries are substituted for the EV batteries with LMO positive electrodes (Fig. 7). However, the savings for the EV batteries, which represent a large fraction of the total cost and value of the plant product, is substantial. The result is that the total cost savings for the annual product from the flex plant producing the NMC-441 EV batteries versus the flex plant producing all LMO batteries is $\$ 38.3$ million ( $\$ 559.1 \mathrm{M}$ vs. $\$ 520.8 \mathrm{M}$ ), which includes an increase in annual cost for the three smaller LMO batteries totaling $\$ 1.5$ million.

Figure 7. Cost of batteries produced in flexible plants with $100-\mathrm{mm} \times 300-\mathrm{mm}$ electrodes meeting the goals of Table 2.1. In one of the plants, the EV batteries have NMC441 positive electrodes; in the other plant, all batteries have LMO positive electrodes. 


\section{Plant Utilization and Learning Curves for Flex Plants}

In the early stages of operation, a battery plant may operate at far below its full capacity, which in the BatPaC model is based on three-shift operation for 300 days per year. BatPaC does allow for launch costs during the initial startup while personnel are being trained and the yield of acceptable product is low. These launch costs apply for only the first few months of operation and the extra labor and materials costs are added to the plant investment as a depreciable item. However, below-capacity production may continue for several years, resulting from difficulties in achieving an acceptable product yield or from lower than anticipated sales.

Small manufacturing plants devoted to manufacturing HEV batteries at less than full-scale production can be converted over several years to flexible plants producing several types of electric-drive batteries at nearly $100 \%$ of the plant capacity. To evaluate the effects of gradually converting a small dedicated plant to a large flex plant, we consider a scenario where the evolution takes place during five stages of plant development (Table 7). In the first stage, only HEV batteries of the type described in Table 3 are produced at a rate of 60,000 batteries per year, $60 \%$ of the maximum utilization of the plant capability available in that stage. In each of the next three stages, another of the batteries described in Table 3 is added to manufacturing. Also, the plant utilization is increased by $10 \%$ in each stage to reach 
$90 \%$ of full capacity in Stage 4. Finally, in Stage 5 the production rate is increased to $100 \%$ of full capacity and the plant reaches the cost distributions of Table 5 .

Table 7 Stages of development of a flexible plant producing the LMO batteries of Table 3 with gradual increases in production volume, types of batteries produced, and plant utilization

The decrease in the unit price and the cost of energy storage capability for each of the batteries is illustrated in Figure 8 as a plant producing a single battery type evolves into a flex plant producing four different types of batteries. The EV batteries show a low cost of energy storage $\left(\$-\mathrm{kWh}^{-1}\right)$ because the cells are thick and contain many thick electrodes resulting in a low area to be coated and a moderate number of cells to be handled per kWh of storage. Referring back to Table 3.2, the EV batteries represent only $13 \%$ of the total flex plant pack capacity, yet dominated the plant resources by accounting for $58 \%$ of the electrode materials, $37 \%$ of the cells, and 38\% of the dry room area. Consequently EV batteries benefit from the economies of scale even at the moderate production level of 30,000 packs per year because of the large number of electrodes and cells in a single battery pack.

Other production growth scenarios than that studied here (Table 7) could be considered, but based on the trends shown in Fig. 8 some general observations are apparent. These are: 
- Higher combined production rate reduces the cost of all battery packs.

- Low-energy battery packs (e.g., HEV) benefit the most from economies of scale for a flexible plant because of the relatively large increase in production volume for each step in the production process.

- High-energy battery packs (e.g., EV) benefit the least because dedicated plants for only moderate numbers of packs per year $(30,000)$ require high production rates for electrodes and the increase in the production rate in a flex plant results in only moderate improvement in overall unit cost.

Figure 8. Cost of battery packs to OEMs and cost of energy stored for four types of batteries as plant production level is increased in a flexible plant as presented in Table 7.

\section{Future Reductions in Cost}

This study addresses only the effects of the scale of manufacture on the cost of lithium-ion batteries and the use of flex plants to increase the effective scale for a single plant. Other improvements are needed to fully meet the cost goals set for EV batteries by the US Advanced Battery Consortium [24-25].

As indicated in Section 5.3, the cost for a flex plant (total production 135,000 per year) could reach as low as $188 \$-\mathrm{kWh}^{-1}$ for production of $30,000 \mathrm{EV}$ batteries per year with NMC chemistry and 35.3-kWh energy. A further indication of the economy of scale is that dedicated plants producing 200,000 and 500,000 such batteries per 
year could reduce the cost to 172 and $161 \$-\mathrm{kWh}^{-1}$, respectively. Although these reductions in cost illustrate the importance of the economy of scale, it is evident that other improvements are required to reach the goals of the USABC, which has set a cost target of $\$ 125$ per usable $\mathrm{kWh}$ at end of life. To meet the goals, the battery cost must be reduced by about 20 to $40 \%$, depending upon the production level. Part of this improvement in cost is likely to result from the reductions in the mass and volume of the battery called for by the USABC; less material may result in lower cost. The use of silicon-containing negative electrodes, higher specific-capacity positive electrodes and improvements in the cell and battery hardware may result in meeting the goals for battery mass and volume [26-27]. It is clear, however, that there will be much pressure to reduce the cost of processing by means of automation and the use of lower cost materials.

\section{Conclusions}

- To take full advantage of cost savings that are derived from increasing the production level in a plant designed to produce lithium batteries for several types of electric vehicles, all batteries must be designed to be produced on the same lines of equipment with little change in the equipment settings.

- For prismatic flat-plate cells, which is the design of the BatPaC model and that chosen for this study, all types of vehicle batteries can be manufactured on the same line of equipment if all of the electrodes have the same width and length. 
- The battery pack power and capacity targets can be met to within 1 to $3 \%$ by manually adjusting the cell thickness and the number of cells per battery pack; BatPaC will automatically select the electrode thickness.

- The battery voltages for single strings of series-connected cells are appropriate for HEV and PHEV batteries, but EV batteries require parallel connections to avoid excessive voltages $(>400 \mathrm{~V})$.

- In a similar way, battery packs with cylindrical or flat wound cells can be manufactured in a flex plant by using the same width for all electrode windings, but cylindrical cells are limited in capacity to facilitate heat dissipation, and thus require many cells in parallel connection to avoid excessive pack voltage.

- The savings in both unit cost and investment cost are substantial for manufacturing HEV batteries in a large flexible plant because of savings in coating and slitting the electrodes on high-speed equipment designed to handle the high production level needed for the PHEV and EV batteries.

- On the other hand, a plant dedicated to producing $60,000-\mathrm{yr}^{-1} \mathrm{EV}$ packs could produce at the same unit cost as for the $30,000 \mathrm{EV}$ packs produced per year in the flex plant $\left(235,000-\mathrm{yr}^{-1}\right.$ total packs $)$ of this study; for production of more than 60,000-yr-1 EV packs, there would be only a little advantage for a flex plant. 
- The minimum cost of energy calculated by BatPaC for large-scale manufacturing (500,000-yr-1 EV packs) is for production of NMC-G EV batteries at about $\$ 161-\mathrm{kWh}^{-1}$ (total energy) or about $\$ 189-\mathrm{kWh}^{-1}$ (usable energy) compared to the USABC target of $\$ 125$ (useable energy). Further reduction in cost will require improved electrodes or other significant changes in the manufacturing process.

- The best single measure of the cost of producing batteries in the example flex plant of this study is the electrode area of the battery, for which the cost is about \$21- $\mathrm{m}^{-2}$ including the cost of the BMS for the LMO cell chemistry at a production rate of $25,000,000-\mathrm{m}^{2}-\mathrm{yr}^{-1}$ cell area.

\section{Acknowledgments}

The authors wish to acknowledge Gary Henriksen for his help in preparing this manuscript. Support from the Vehicle Technologies Program, Hybrid and Electric Systems, initially under Tien Duong and now David Howell and Peter Faguy, at the U.S. Department of Energy, Office of Energy Efficiency and Renewable Energy, is gratefully acknowledged. The submitted manuscript has been created by UChicago Argonne, LLC, Operator of Argonne National Laboratory ("Argonne"). Argonne, a U.S. Department of Energy Office of Science laboratory, is operated under contract no. DE-AC02-06CH11357. The U.S. Government retains for itself, and others acting on its behalf, a paid-up nonexclusive, irrevocable worldwide license in said article to 
reproduce, prepare derivative works, distribute copies to the public, and perform publicly and display publicly, by or on behalf of the Government.

\section{Glossary}

ASI Area specific impedance

EV Electric vehicle

BMS Battery management system

HEV Hybrid electric vehicles

LMO Lithium manganite spinel/graphite, $\mathrm{Li}_{1.05} \mathrm{Mn}_{1.94-\mathrm{x}} \mathrm{M}_{\mathrm{x}}^{\prime} \mathrm{O}_{4} / \mathrm{C}_{6}$

NMC Nickel manganese cobalt oxide/graphite, $\mathrm{Li}_{1.05}\left(\mathrm{Ni}_{4 / 9} \mathrm{Mn}_{4 / 9} \mathrm{Co}_{1 / 9}\right)_{0.95} \mathrm{O}_{2} / \mathrm{C}_{6}$

OCV Open circuit voltage

OEM Original equipment manufacturer

$\mathrm{P} / \mathrm{E} \quad$ Power to energy ratio

PHEVxx Plug-in hybrid vehicle with a range of $x x$ miles

SOC State of Charge 


\section{References}

1. P. Nelson, I. Bloom, K. Amine, G. Henriksen, Journal of Power Sources, 110, (2002) 437.

2. P. Nelson, D. Dees, K. Amine, G. Henriksen, Journal of Power Sources, 110, (2002) 349.

3. G.L. Henriksen, K. Amine, J. Liu, and P.A. Nelson, "Materials Cost Evaluation Report for High-Power Li-Ion HEV Batteries," Electrochemical Technology Program, Chemical Technology Division, Argonne National Laboratory, ANL03/05, Argonne, IL (2002).

4. P. Nelson, K. Amine, A. Rousseau, H. Yomoto, "Advanced Lithium-Ion Batteries for Plug-in Hybrid-Electric Vehicles", International Electric Vehicles Symposium, EVS-23, Anaheim, Ca (2007).

5. P.A. Nelson, K. G. Gallagher, I. Bloom, and D. W. Dees, "Modeling the Performance and Cost of Lithium-Ion Batteries for Electric Vehicles, Second Edition" Chemical Sciences and Engineering Division, Argonne National Laboratory, ANL-12/55, Argonne, IL USA (2011).

6. BatPaC (Battery Performance and Cost) Software, P.A. Nelson, K.G. Gallagher, and I. Bloom, (2012) available from http://www.cse.anl.gov/BatPaC/ 
7. K. G. Gallagher and P. A. Nelson, "Manufacturing Costs of Batteries for Electric Vehicles," Chapter 6 in Lithium-Ion Batteries Advances and Applications ,Ed. G. Pistoria, Elsevier, Amsterdam (2014).

8. G. Patry, A. Romagny, S. Martinet, D. Froelich "Cost modeling of lithium-ion battery cells for automotive applications" Energy Science \& Engineering 3(1) 7182 (2015).

9. A. Sakti, J. J. Michalek, E.R.H. Fuch, J. F. Whitacre "A techno-economic analysis and optimization of Li-ion batteries for light-duty passenger vehicle electrification" J. Power Sources 273(1) 966-980 (2015).

10. TIAX LLC, “Cost Assessment for Plug-In Hybrid Vehicles (SOW-4656)," Report to US DOE Office of Transportation Technology, October (2007).

11. P. Mock, "Assessment of Future Li-Ion Battery Production Costs," presented at Plug-in 2009, Long Beach, CA, (2009).

12. S.S. Shawn, T.H. Kim, S.J. Hu, W.W. Cai, J.A. Abell, “A State-of-the-Art Review on Lithium-Ion Battery Joining, Assembly and Packaging in Battery Electric Vehicles," International Electric Vehicles Symposium EVS-25, Shenzhen, China, (2010).

13. W. Mareike, D. Leiva, M. Fritsch, S. Borner, “Process Development and Optimization for Li-Ion Battery Production," International Electric Vehicles Symposium EVS-27, (2014).

14. S. Benjaafar, S.S. Heragu, S.A. Irani, "Next Generation Factory Layouts: Research Challenges and Recent Progress," Interfaces 32(6) 58-75, (2002). 
15. J. Balakrishnan, C.H. Cheng, "Multi-period Planning and Uncertainty Issues in Cellular Manufacturing: A Review and Future Directions," European Journal of Operational Research 177 281-309, (2007).

16. P.A. Nelson, D.J. Santini, J. Barnes, “Factors Determining the Manufacturing Costs of Lithium-Ion Batteries for PHEVs." International Electric Vehicles Symposium EVS-24, Stavanger, Norway, (2009).

17. D.J. Santini, K.G. Gallagher, P.A. Nelson, "Modeling the Manufacturing Costs of Lithium-Ion Batteries for HEVs, PHEVs, and EVs," International Electric Vehicles Symposium EVS-25, Shenzhen, China, (2010).

18. P. Nelson, "Modeling the Manufacturing Costs of Lithium-Ion Batteries for PHEVs," presented at Plug-in 2009, Long Beach, CA, (2009).

19. K.G. Gallagher, P.A. Nelson, and D.W. Dees, Journal of Power Sources, 196 (2011) 2289.

20. L. Gaines and R. Cuenca, "Costs of Lithium-Ion Batteries for Vehicles," Center for Transportation Research, Energy Systems Division, Argonne National Laboratory, ANL/ESD-42, Argonne, IL May (2000).

21. A.K. Coker, "Ludwig's Applied Process Design for Chemical Plants," Chapter 2, "Cost Estimation and Economic Evaluation," Volume 1, Fourth Edition, Elsevier Inc. (2007).

22. R.H. Perry, D.W. Green, "Perry's Chemical Engineers' Handbook," Eighth Edition, “Process Economics," Section 9, McGraw-Hill, New York, N.Y., (2007). 
23. Tesla to build Gigafactory battery plant in Nevada, reports say http://www.cse.bizjournals.com/sanjose/news/2014/09/03/tesla-choosesnevada-for last accessed October 13, 2014.

24. J. Neubauer, A. Pesaran, C Bae, R Elder, B. Cunningham, “Updating United States Advanced Battery Consortium and Department of Energy battery technology targets for battery electric vehicles," Journal of Power Sources, 271 (2014) 614.

25. Development of Advanced High Performance Batteries for Electric Vehicle (EV) Applications: Request for Proposal Information (RFPI), United States Advanced Battery Consortium LLC, September 18, 2013.

26. S.-H. Kang, W. Lu, K.G. Gallagher, S.-H. Park, “Study of $\mathrm{Li}_{1+x}\left(\mathrm{Mn}_{4 / 9} \mathrm{Co}_{1 / 9} \mathrm{Ni}_{4 / 9}\right)_{1-\mathrm{x}} \mathrm{O}_{2}$ Cathode Materials for Vehicle Battery Applications, Journal of The Electrochemical Society, 158 (8) A936-A941 (2011).

27. K.G. Gallagher, S. Goebel, T. Greszler, M. Mathias, W. Oelerich, D. Eroglu, V. Srinivasan, "Quantifying the promise of lithium-air batteries for electric vehicles," Energy \& Environmental Science, 2014, 7, 1555. 


\section{Table 1}

Example of battery pack parameters and production volumes for manufacturing in a flexible plant

\begin{tabular}{|l|r|r|r|r|}
\hline Vehicle type & HEV & PHEV10 & PHEV40 & EV \\
\hline Vehicle range (miles)* & 1.25 & 10 & 40 & 150 \\
\hline Target total energy (kWh)* & 1.0 & 2.86 & 11.4 & 35.3 \\
\hline Available battery energy (\% of total) & 25 & 70 & 70 & 85 \\
\hline Target power for 10 seconds (kW) & 35 & 65 & 130 & 150 \\
\hline Annual production volume (235,000 total) & 100,000 & 60,000 & 45,000 & 30,000 \\
\hline
\end{tabular}

*Assumes efficient, light-weight vehicles with energy requirements on the UDDS cycle of 200 Wh-mile-1. 


\section{Table 2}

Distribution of processing rates and dry room area among battery types; 100mm x 300-mm electrodes.

\begin{tabular}{|l|r|r|r|r|r|}
\hline & \multicolumn{5}{|c|}{ Processing Rates, \% of Total Flexible Plant } \\
\hline Battery Type & HEV & PHEV10 & PHEV40 & EV & Flex \\
\hline Production Rate, Packs per Year & 100,000 & 60,000 & 45,000 & 30,000 & 235,000 \\
\hline Packs per Year, \% of Total & 43 & 26 & 19 & 13 & 100 \\
\hline Energy Storage, \% of Total & 5 & 9 & 28 & 57 & 100 \\
\hline Cells, \% of Total & 17 & 22 & 25 & 37 & 100 \\
\hline Electrode Materials, \% of Total & 5 & 9 & 28 & 58 & 100 \\
\hline Electrode Area, \% of Total & 11 & 17 & 25 & 47 & 100 \\
\hline Dry Room Area, \% of Total & 16 & 21 & 25 & 38 & 100 \\
\hline
\end{tabular}




\section{Table 3}

Selected parameters for batteries to meet goals of Table 1 with lithium manganite spinel/graphite (LMO) cell chemistry and 100-mm x 300-mm positive electrodes

\begin{tabular}{|l|r|r|r|r|}
\hline Vehicle Type & HEV & PHEV10 & PHEV40 & \multicolumn{1}{c|}{ EV } \\
\hline Cell capacity, Ah & 11.6 & 15.5 & 41.3 & 57.5 \\
\hline Cell thickness, mm & & & & \\
$\quad \begin{array}{l}\text { Default BatPaC thickness } \\
\text { Selected thickness }\end{array}$ & 6.0 & 8.0 & 8.0 & 12.0 \\
\hline Number of two-sided positives per cell & 4.9 & 6.1 & 13.1 & 17.8 \\
\hline Number of cells in parallel & 23 & 26 & 34 & 43 \\
\hline Total cells in pack & 1 & 1 & 1 & 2 \\
\hline Coating thickness, microns & 22 & 48 & 72 & 160 \\
\hline $\begin{array}{l}\text { Cathode } \\
\text { Anode }\end{array}$ & & & & \\
\hline Nominal battery voltage (OCV at 50\% SOC), V & 87 & 45 & 91 & $100^{*}$ \\
\hline Maximum battery current at full power, A & 506 & 454 & 601 & $525^{*}$ \\
\hline Power at 80\% OCV, kW & & & & 61 \\
\hline Target & 35 & 65 & 130 & 150 \\
\hline Actual & 35.2 & 66.7 & 132.4 & $369 *$ \\
\hline Energy Storage, kWh & & & & \\
\hline Target & 1.0 & 2.86 & 1.42 & 35.29 \\
\hline Actual & 1.01 & 2.94 & 11.66 & 36.06 \\
\hline Vehicle range at 200 Wh-mile- & 1.3 & 10.3 & 40.8 & 153.2 \\
\hline
\end{tabular}


*The limit on the thickest electrode (100 microns) results in more electrode area than necessary to meet the power requirement at $80 \% \mathrm{OCV}$. Accordingly, the battery power would be limited to the target value of $150 \mathrm{~kW}$ by a current limit. 


\section{Table 4}

Effects of over sizing and under sizing battery; EV battery with LMO cell chemistry and100-mm x 300-mm electrodes

\begin{tabular}{|l|r|r|}
\hline & Over Sized & Under Sized \\
\hline Number of cells & 160 & 160 \\
\hline Number of electrodes per cell & 43 & 42 \\
\hline Target energy, kWh & 35.3 & 35.3 \\
\hline Actual energy, kWh & 36.1 & 35.2 \\
\hline Unit price*, \$ & $8,150.80$ & $8,019.04$ \\
\hline Cost of energy* \$-kWh $^{-1}$ & 226.05 & 227.69 \\
\hline
\end{tabular}

${ }^{*}$ Cost of pack to vehicle OEM including battery management system (BMS), e.g. state of charge (SOC), control at module level, safety monitoring, breakers, etc. 


\section{Table 5}

Distribution of product cost for flexible plant producing LMO batteries with 100mm x 300-mm electrodes including the BMS units

\begin{tabular}{|l|r|r|r|r|r|}
\hline Battery Type & HEV & PHEV10 & PHEV40 & EV & Flex Plant \\
\hline Production per Year & $\mathbf{1 0 0 , 0 0 0}$ & $\mathbf{6 0 , 0 0 0}$ & $\mathbf{4 5 , 0 0 0}$ & $\mathbf{3 0 , 0 0 0}$ & $\mathbf{2 3 5 , 0 0 0}$ \\
\hline Cost of annual product, \$mil & 71 & 97 & 146 & 245 & 559 \\
\hline Total investment, \$mil & 48 & 67 & 101 & 176 & 391 \\
\hline Annual product/investment, ratio & 1.50 & 1.45 & 1.45 & 1.39 & 1.43 \\
\hline Unit product cost, \$/pack & 714 & 1,614 & 3,250 & 8,151 & \\
\hline Product cost, \% of total & 13 & 17 & 26 & 44 & 100 \\
\hline Product cost per area, \$-m ${ }^{-2}$ & 24 & 22 & 22 & 20 & 21 \\
\hline Unit cost saving, \% & 21 & 18 & 14 & 9 & 14 \\
\hline Investment cost savings, \% & 43 & 38 & 31 & 21 & 28 \\
\hline
\end{tabular}




\section{Table 6}

Comparison of EV battery designs with LMO or NMC positive electrodes (100 mm W x $300 \mathrm{~mm} \mathrm{~L}$ ) manufactured in flex plants

\begin{tabular}{|l|r|r|}
\hline Cell Chemistry & LMO & NMC \\
\hline Total cells in pack & 160 & 160 \\
\hline Specific capacity of positive electrode, mAh-g-1 & 100 & 175 \\
\hline Cell capacity, Ah & 57.5 & 61.3 \\
\hline Number of two-sided electrodes per cell & 43 & 29 \\
\hline Cell thickness, mm & 17.8 & 14.4 \\
\hline Nominal battery voltage (OCV at 50\% SOC), V & 316 & 300 \\
\hline Battery power, $\mathrm{kW}$ & 150 & 150 \\
\hline Voltage at full power, \% of OCV & 93.0 & 81.9 \\
\hline Energy stored, $\mathrm{kWh}$ & 36.1 & 36.2 \\
\hline Vehicle range, miles & 153.2 & 154.0 \\
\hline Specific energy, Wh-kg-1 & 122.8 & 159.3 \\
\hline Cost of positive active material, \$-kg ${ }^{-1}$ & 10.00 & 26.00 \\
\hline Cost per cell area, \$-m ${ }^{-2}$ & 20 & 25 \\
\hline Cost of energy storage, \$-kWh ${ }^{-1}$ & 226 & 188 \\
\hline
\end{tabular}




\section{Table 7}

Stages of development of a flexible plant producing the LMO batteries of Table 3 with gradual increases in production volume, types of batteries produced, and plant utilization

\begin{tabular}{|c|c|c|c|c|c|c|}
\hline \multirow{2}{*}{$\begin{array}{l}\text { Stage of } \\
\text { Development }\end{array}$} & \multicolumn{5}{|c|}{ Pack Production Volume (thousands per year) } & \multirow{2}{*}{$\begin{array}{l}\text { Plant } \\
\text { Utilization (\%) }\end{array}$} \\
\hline & HEV & PHEV10 & PHEV40 & EV & Flex Plant & \\
\hline 1 & 60 & & & & 60 & 60 \\
\hline 2 & 70 & 42 & & & 112 & 70 \\
\hline 3 & 80 & 48 & 36 & & 164 & 80 \\
\hline 4 & 90 & 54 & 40.5 & 27 & 212 & 90 \\
\hline 5 & 100 & 60 & 45 & 30 & 235 & 100 \\
\hline
\end{tabular}




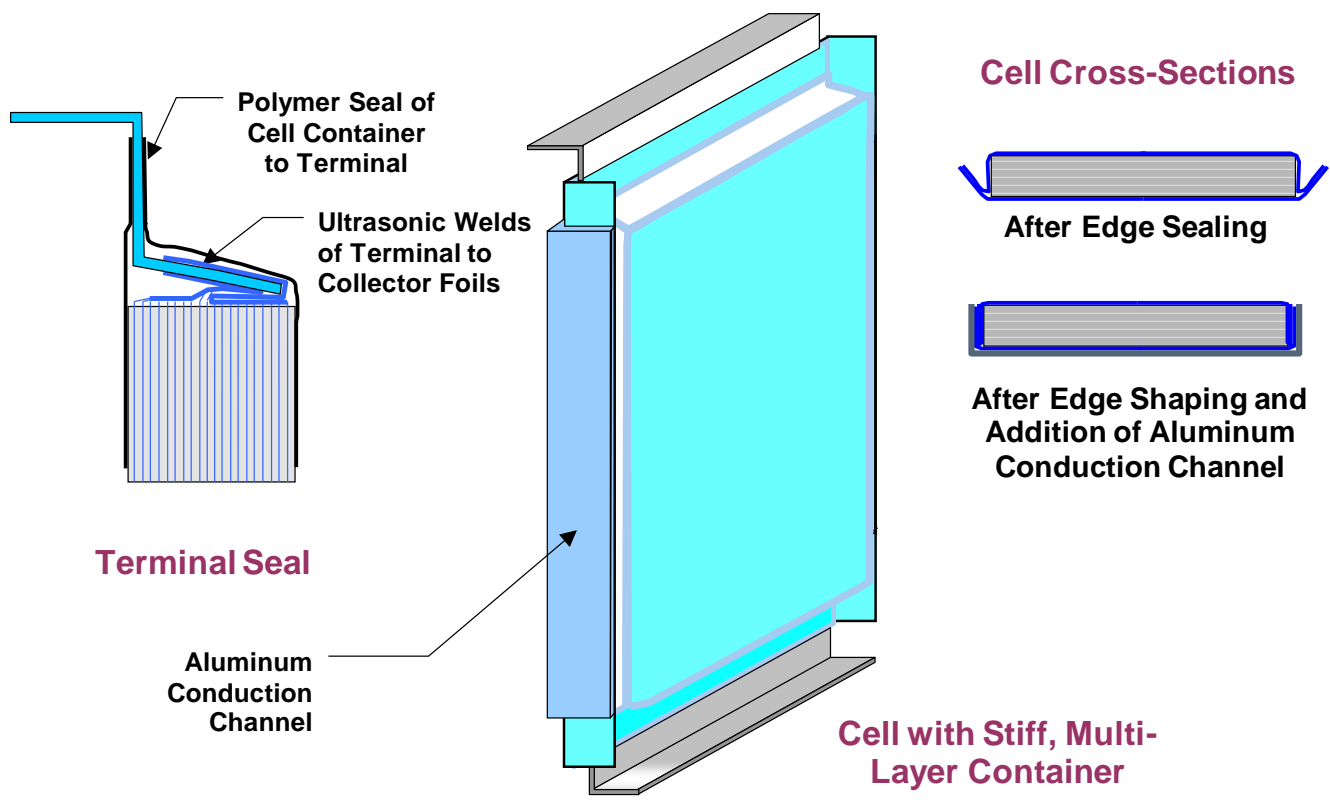

Figure 1. Prismatic cell in stiff pouch container with aluminum conduction channel added for heat rejection from a liquid-cooled module 


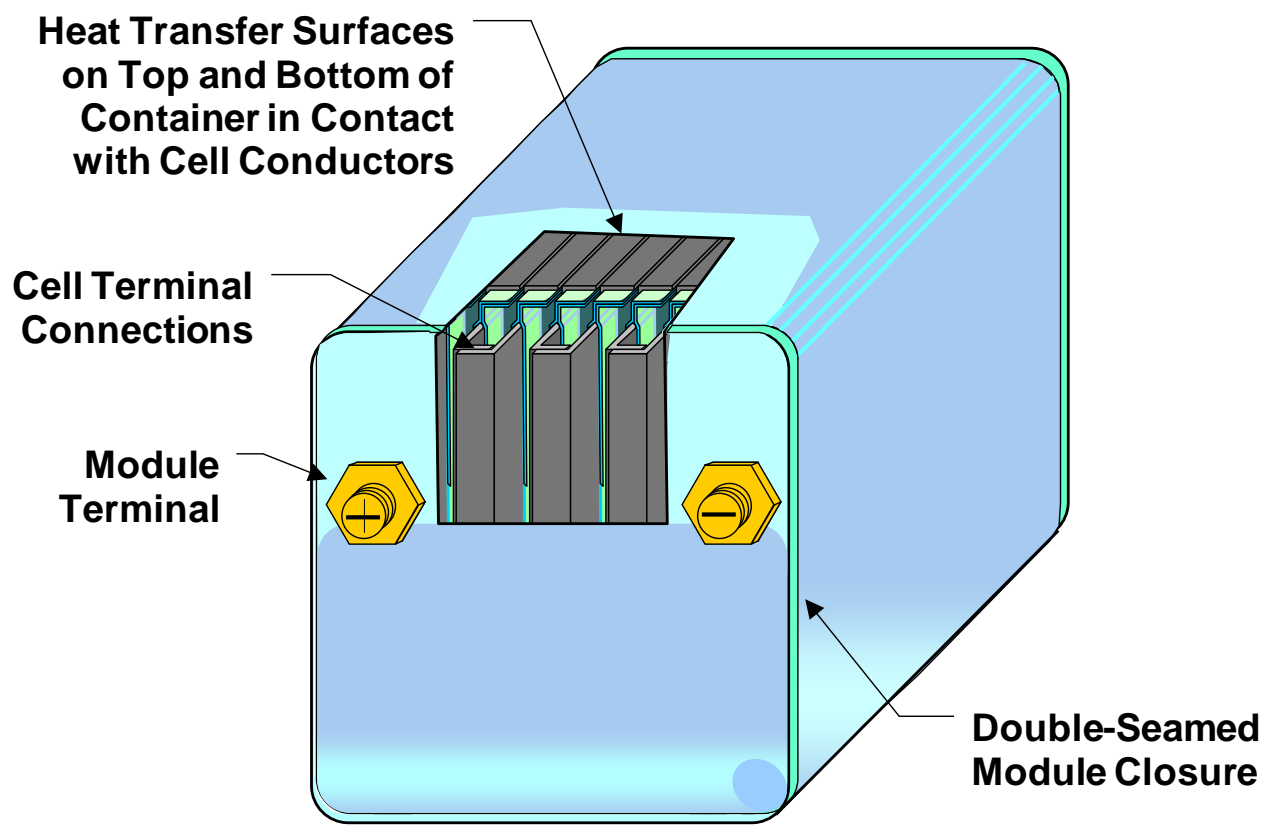

Figure 2. Module with hermetically sealed aluminum container for liquid cooled batteries 


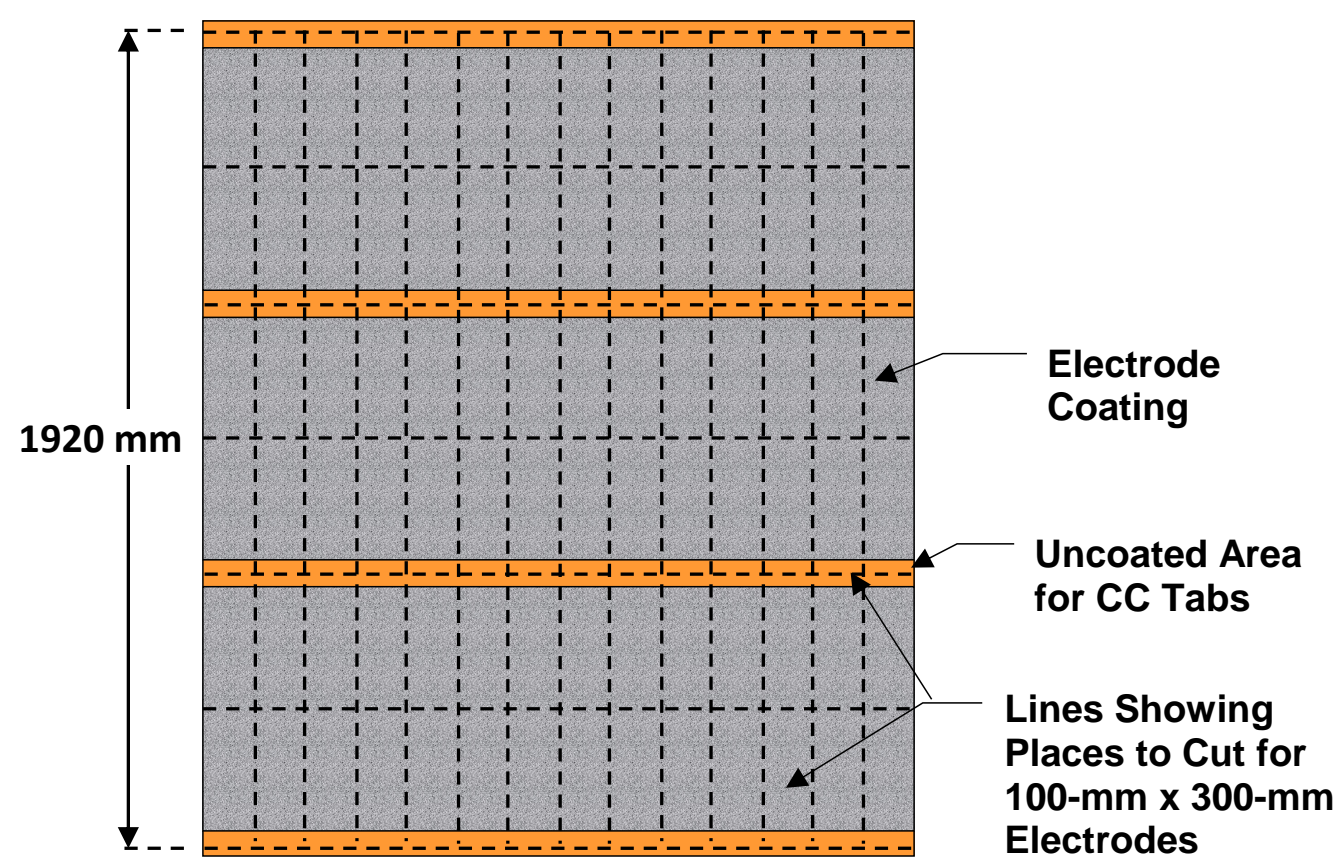

Figure 3. Sample layout of electrode coating on current collector foil 

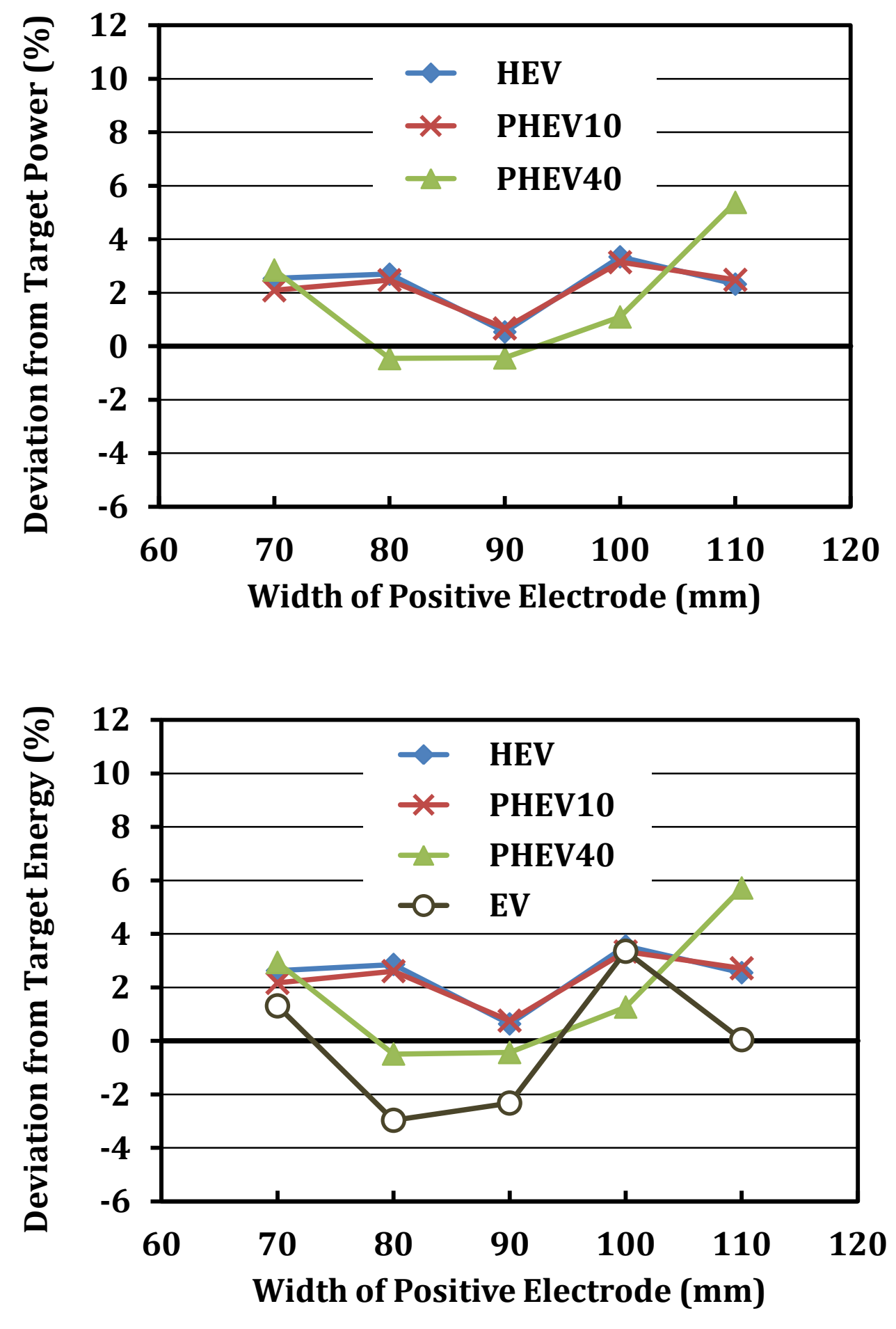

Page 1 of 2 
Figure 4. Deviations from target power and target energy for four types of batteries (see Table 1) for five levels of positive electrode widths and a length-towidth ratio of 3.0. 

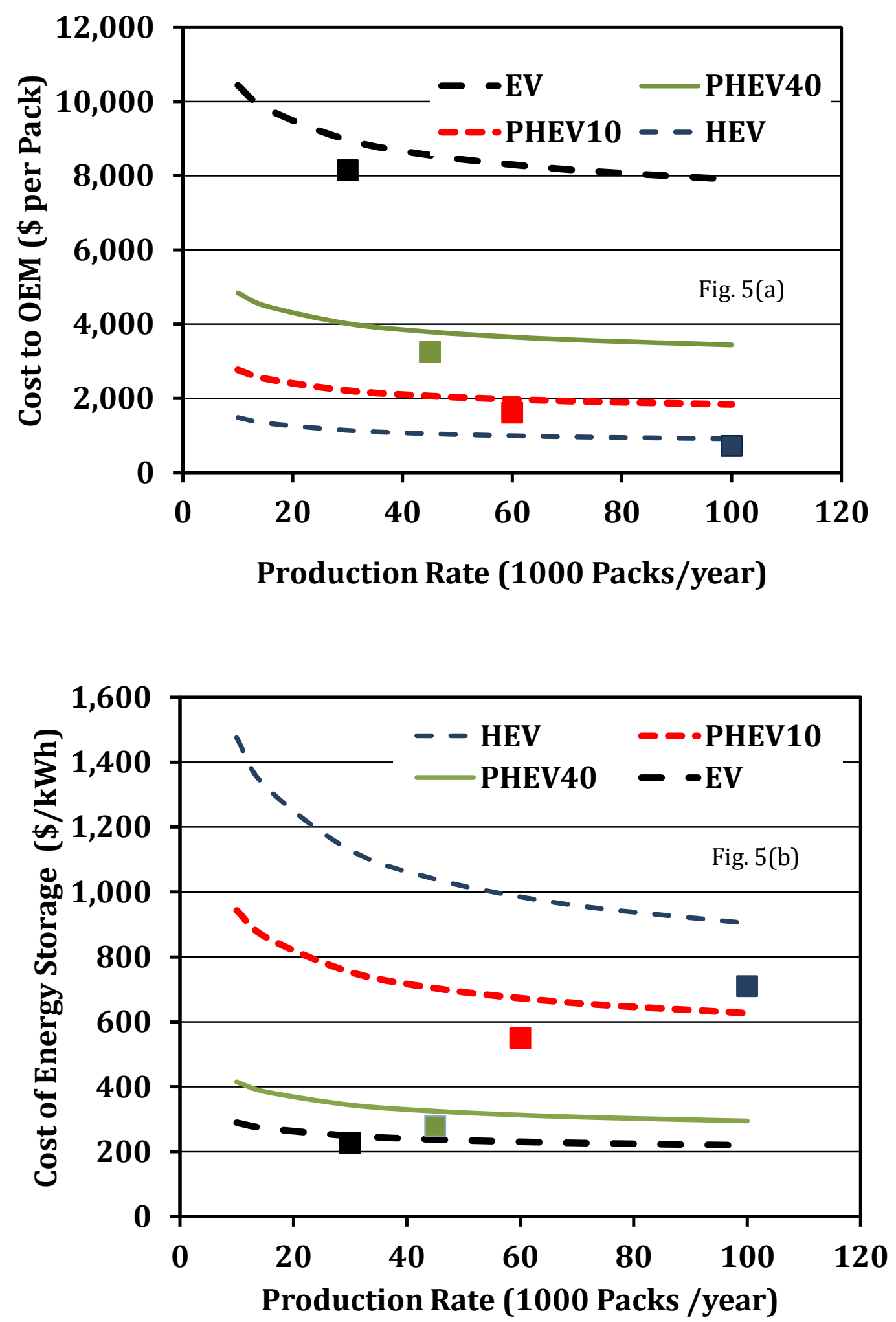

Page 1 of $\mathbf{2}$ 
Figure 5 Unit cost per battery pack and cost of energy storage (including the BMS) for LMO batteries manufactured at the indicated rates in plants dedicated to a single battery type producing at $100 \%$ capacity (lines) and in a flex plant producing all of the batteries at $100 \%$ of the 235,000 packs per year capacity (markers); all positive electrodes measure $100-\mathrm{mm}$ by $300-\mathrm{mm}$. 


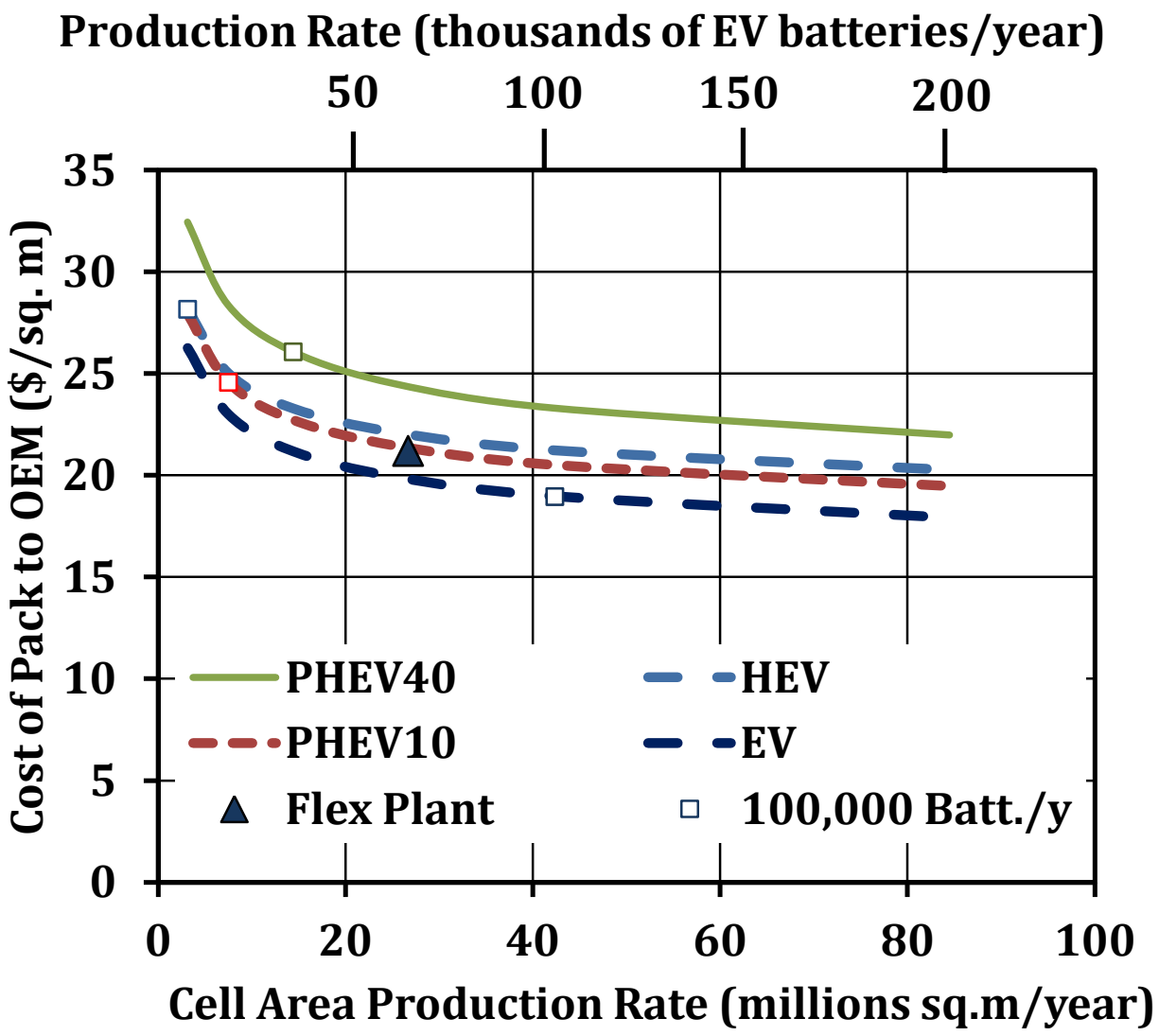

Figure 6. Cost of battery packs as a function of cell area and production rate for production in plants dedicated to a single type of battery 


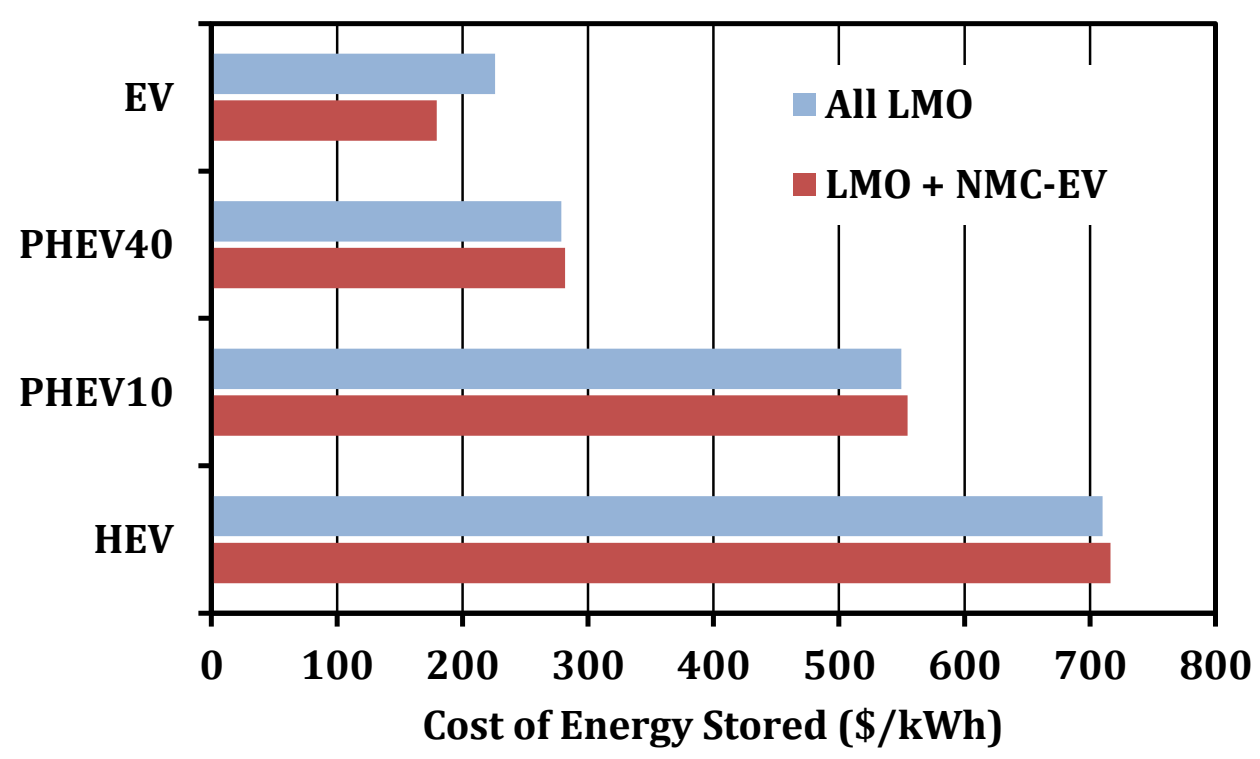

Figure 7. Cost of batteries produced in flexible plants with $100-\mathrm{mm} \times 300-\mathrm{mm}$ electrodes meeting the goals of Table 1. In one of the plants, the EV batteries have NMC441 positive electrodes; in the other plant, all batteries have LMO positive electrodes 


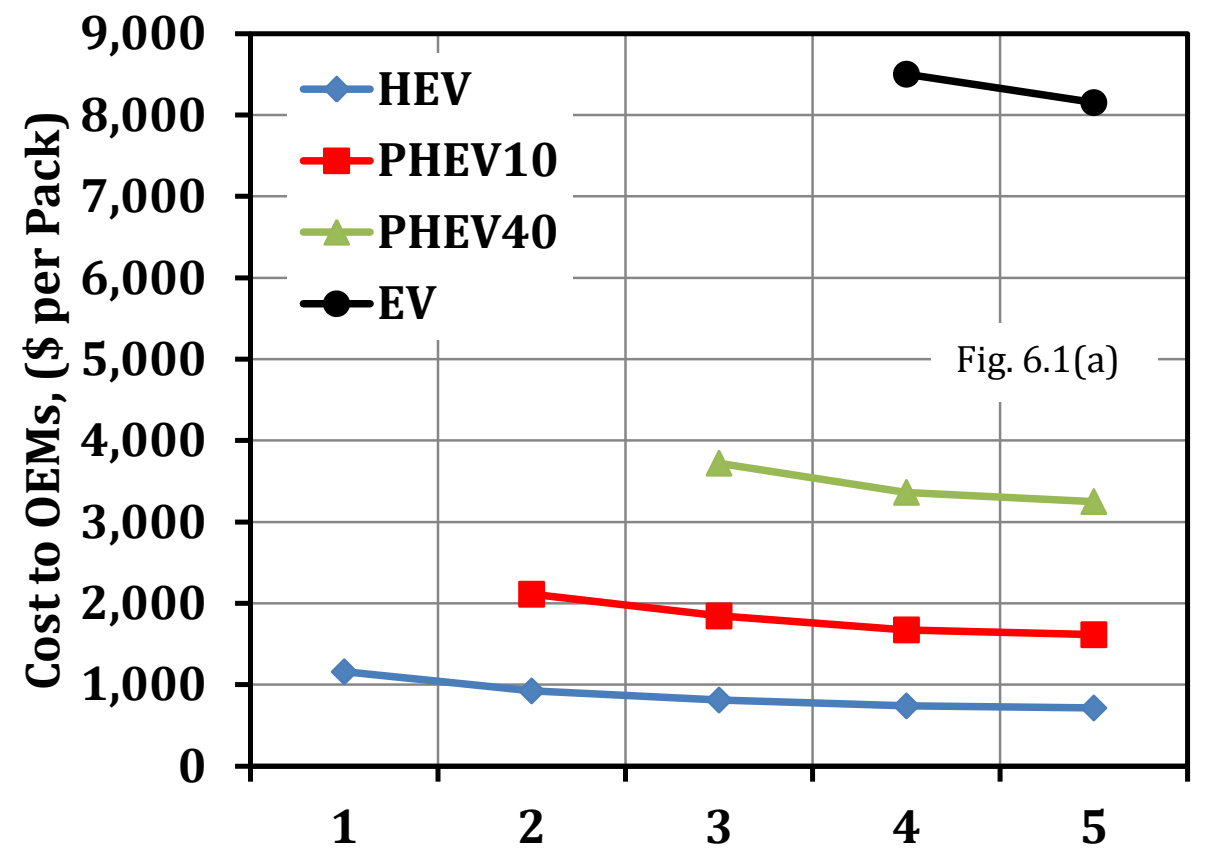

Stage of Production Plant Development

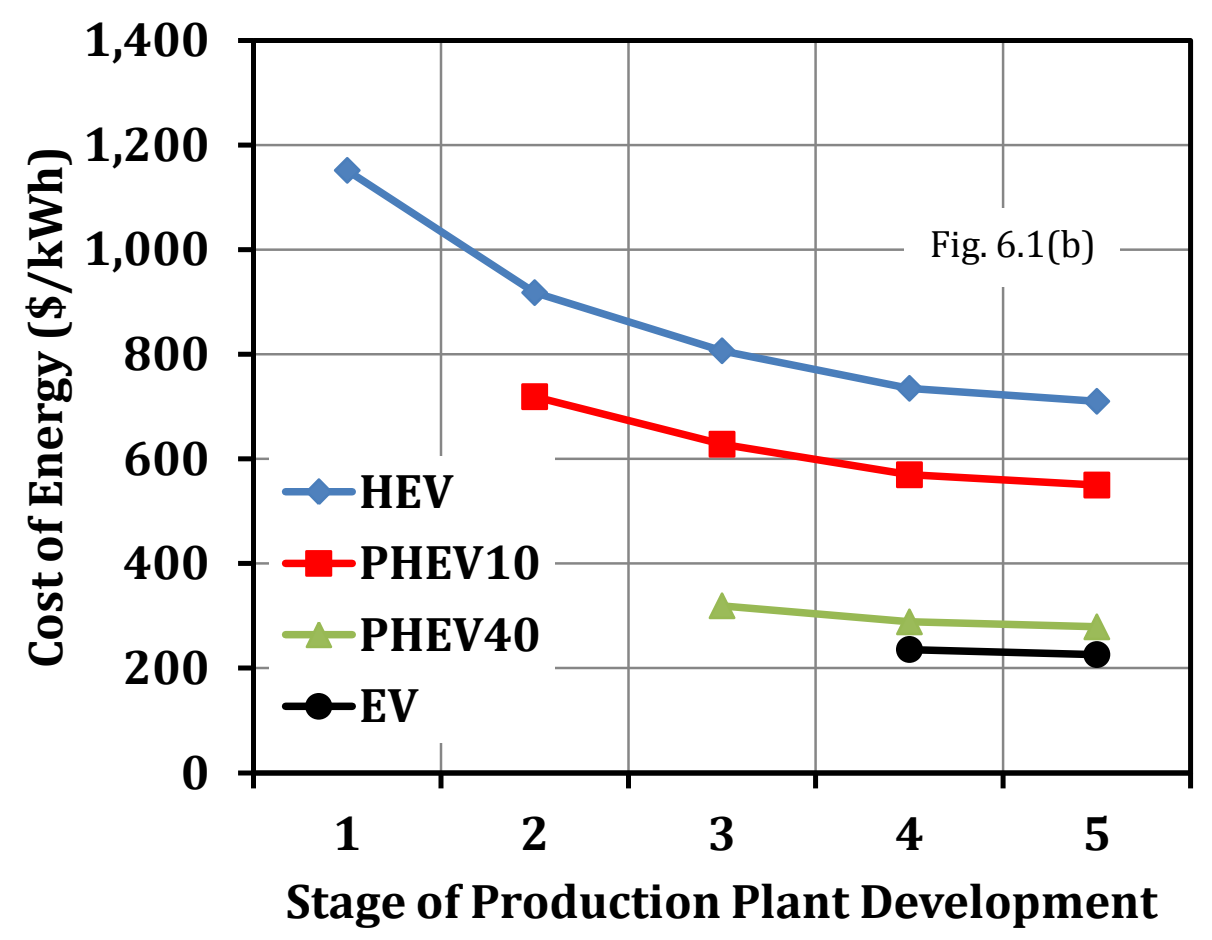

Page 1 of 2 
Figure 8. Cost of battery packs to OEMs and cost of energy stored for four types of batteries as plant production level is increased in a flexible plant as presented in Table 7. 